\title{
TEORIA DA BASE DE EXPORTAÇÃO E SUA RELAÇÃO COM O DESEMPENHO ECONÔMICO: O CASO DO ESTADO DE SANTA CATARINA
}

\author{
Elaine Carvalho de Lima' \\ Érica Priscilla Carvalho de Lima² \\ Inauro Mano Evas ${ }^{3}$ \\ Maria do Socorro Gondim Teixeira ${ }^{4}$
}

\section{RESUMO}

O presente trabalho pretende examinar o desempenho econômico do estado de Santa Catarina a partir do referencial teórico da Teoria da Base de Exportação. Analisa-se a distribuição setorial das atividades no estado para identificar quais são os setores chaves para o seu desempenho, no período pós 1990. Com vistas a atender esse objetivo, realizou-se uma construção teórica sobre a temática e utilizaram-se os métodos de análise regional e de especialização, especificamente o Quociente Locacional (QL) e o Coeficiente de Reestruturação. Os principais resultados indicaram que a indústria é o setor básico (de exportação) da economia catarinense, reafirmando seu padrão de especialização no setor. Ademais, a base de exportação do estado não propiciou o crescimento de outras atividades de exportação, embora tenha se verificado a perda do valor adicionado da indústria em detrimento do aumento do setor de serviços na última década. Desta forma, ressalta-se a relevância de pensar em setores estratégicos e políticas públicas que possibilitem uma menor concentração produtiva e maior diversificação setorial.

Palavras Chaves: Base de exportação, desempenho econômico, Santa Catarina.

Classificação JEL: R10.

Mestranda em Economia pela Universidade Federal do Rio Grande do Norte (UFRN). E-mail: elainecarvalhoonline@ hotmail.com. Fone: (84) 8838-7352

2 Mestranda em Estudos Urbanos e Regionais pela Universidade Federal do Rio Grande do Norte (UFRN). E-mail: ericapriscillaufrn@hotmail.com. Fone: (84) 88387299

3 Mestrando em Economia pela Universidade Federal do Rio Grande do Norte(UFRN). E-mail: inauro_evas@yahoo. com.br. Fone (84) 9844-4670

${ }^{4}$ Professora Dra da Universidade Federal do Rio Grande do Norte (UFRN). E-mail: tmsgondim@uol.com.br. 


\section{INTRODUÇÃO}

O desenvolvimento das atividades no espaço tem um papel importante associado à condição de sucesso ou atraso da região, inclusive possibilitando que uma determinada área possa ser qualificada como um polo industrial, por exemplo. Assim, a escolha de localização ótima das atividades é algo fundamental e aborda questões sobre a proximidade das matérias-primas, redução dos custos de produção, custo com transportes, aumento dos lucros, entre outros fatores.

Nota-se que a preocupação com o crescimento desigual no espaço tem sido estudada por vários autores que objetivam analisar como se desenvolvem e crescem as regiões, muitos desses estudos têm influenciado a ciência regional, tornando-se um arcabouço teórico para a efetivação de políticas econômicas. Nesse sentido, uma das teorias que possui grande importância na análise descrita é a teoria da Base de Exportação desenvolvida por Douglass North, que analisa o desenvolvimento econômico regional a partir da ênfase à atividade exportadora, que fomentaria as outras atividades, estas últimas voltadas ao mercado interno.

O objetivo deste artigo não é realizar uma análise crítica da Teoria da Base de Exportação, doravante chamada TBE, mas usá-la como instrumento de pesquisa capaz de analisar a dinâmica do mercado interno de Santa Catarina (SC) a partir das atividades exportadoras. Dessa forma, o trabalho objetiva contribuir no processo de promoção e construção de políticas públicas para o desenvolvimento regional, ressaltando a importância dos incentivos às políticas de promoção de exportação como forma de dinamizar o desenvolvimento local e minimizar as desigualdades regionais.

Desse modo, busca-se averiguar a relação entre o desenvolvimento do estado de Santa Catarina com a TBE no período pós 1990. Os procedimentos metodológicos utilizados consistiram no levantamento dos dados dos empregos formais no estado, bem como o cálculo do Quociente Locacional e coeficiente de reestruturação nos anos de 1990, 2000 e 2010.

O artigo está estruturado em cinco seções além dessa parte introdutória. A primeira apresenta uma breve contextualização sobre a questão da problemática regional. A seção seguinte faz um resgate teórico sobre a TBE, que norteia o presente estudo. A seção três apresenta a metodologia do 
Teoria da base de exportação e sua relação com o desempenho econômico: o caso do estado de Santa Catarina

trabalho e uma contextualização histórica da economia de Santa Catarina. A quarta seção ilustra os principais resultados obtidos. E por fim têm-se as principais conclusões.

\section{BREVE CONTEXTUALIZAÇÃO: O ESTUDO DO ESPAÇO NA ECONOMIA}

A partir de meados dos anos 1950, as investigações sobre a região e sua gestão tornaram-se mais relevantes na ciência econômica. No primeiro momento, os estudos sobre a região se davam de maneira mais quantitativa, desde a localização das atividades, a forma de organização da produção até mesmo a divisão da população.

De modo geral, a necessidade de estudar a região como um espaço de relações econômicas não é um debate recente, em fins do século XIX, Alfred Marshall analisava a localização das empresas como ambiente gerador de vantagens competitivas. $\mathrm{O}$ autor argumentou a importância da existência de aglomerações produtivas e as externalidades locais geradas em benefício do crescimento da indústria

Um dos autores pioneiros que centralizou seus estudos sobre a configuração do espaço foi Von Thünen (1783-1850), que é considerado o "pai das teorias de localização". Sua análise parte da perspectiva de alguns problemas espaciais presentes na economia de troca, tais como: a influência da cidade sobre o preço dos produtos, as relações entre a cidade e o campo, papel dos transportes na economia, localização ótima das culturas, entre outros fatores. Para o Thünen, a organização espacial pode ser compreendida através das variações da renda dos produtos fundiários e a distância das cidades, desse modo a distância seria inversamente proporcional ao rendimento obtido pela atividade (CLEMENTE, 1994).

Nesse sentido, o surgimento da Ciência Regional ${ }^{5}$ fundamentou as análises sobre a distribuição das atividades econômicas no espaço, permitindo uma melhor compreensão dos vários aspectos que permeiam o ambiente regional.

Benko (1999) enfatiza que no século XX as preocupações relacionadas com as disparidades entre os espaços e seus possíveis desdobramentos

Benko ( 1999 ), ao descrever o processo de gênese e desenvolvimento da Ciência Regional a define como a disciplina do cruzamento, ou seja, da encruzilhada da ciência econômica, geografia, sociologia, da ciência política e da antropologia, daí decorrer a sua complexidade. 
ganham maior relevância. Nesse contexto, a região passa a ser vista como um problema, assim, a utilização de instrumentos regionais passa a contribuir para minimizar tais consequências para as regiões, traduzindo-se na necessidade de políticas públicas como modo de atenuar as desigualdades entre as regiões. Dessa maneira, "a ciência regional (ou a economia espacial) foi fundada par responder aos problemas levantados pela região, ou pela repartição territorial das atividades.” (BENKO 1999, p. 13).

\subsection{Desenvolvimento regional e a emergência das disparidades regionais}

Como mencionado, as discussões sobre o espaço levantam questionamentos sobre a problemática regional. Ao longo das últimas décadas, essas questões ganharam mais ênfase na teoria econômica, se expandindo a nível mundial, evidenciando a dualidade existente entre os países desenvolvidos e subdesenvolvidos. Vários são os enfoques teóricos sobre o modo de crescimento das regiões, que sofre influência da estrutura econômica, das vantagens geográficas, disponibilidade de fatores de produção e até mesmo o ambiente político e institucional poderá influenciar.

Myrdal (1968) mostra que as forças de mercado quando não regulamentadas aumentam as desigualdades regionais, pois, as atividades econômicas se concentram em determinadas áreas devido às vantagens competitivas, em detrimento de outras regiões. Ou seja, algumas regiões irão atrair certas atividades devido a uma série de vantagens competitivas, entre elas, mãode-obra qualificada, disponibilidade de recursos naturais, infraestrutura, entre outros. Em contrapartida, as regiões mais atrasadas seriam prejudicadas, por não possuírem as mesmas vantagens que influenciam na decisão de investimentos nessas áreas é o que o autor definiu como processo de causação circular e cumulativa, ou seja, as regiões desenvolvidas tendem a desenvolver-se cada vez mais (círculo virtuoso) e as subdesenvolvidas tendem a empobrecerem cada vem mais (circulo vicioso).

Já para Perroux (1967), em sua "Teoria do Crescimento Polarizado", o crescimento não se dá em todos os espaços, há uma manifestação em pólos de crescimento nas mais diversas formas. De modo que os espaços polarizados sofrem a ação do campo de forças de atração (centrípetas) e de repulsão (centrífugas). Tal relação é exemplificada por Clemente (1994), que afirma que uma empresa pode exercer forças de atração por mão de 
Teoria da base de exportação e sua relação com o desempenho econômico: o caso do estado de Santa Catarina

obra e fornecedores de matéria-prima e desempenhar forças de repulsão sobre possíveis concorrentes.

$\mathrm{Na}$ análise Perrouxiana, utiliza-se a noção de espaço econômico (abstrato) por se tratar de um termo mais amplo referente a intervenção do homem no espaço, assumindo as mais diversas relações econômicas. $\mathrm{O}$ autor enfatiza as relações existentes entre indústrias classificadas como motrizes, que influencia a expansão através de seus fluxos e rendas geradas para outras indústrias. Há também as indústrias movidas, que têm seu crescimento dependente das indústrias motrizes. A indústria motriz gera economias de aglomeração formando complexos industriais localizados, assim, a expansão regional é reflexo do crescimento dessas indústrias que formam o núcleo de desenvolvimento.

A partir das teorias citadas verifica-se que o desenvolvimento das atividades no espaço tem um papel importante associado a condição de sucesso ou atraso da região, inclusive possibilitando que uma determinada área possa ser qualificada como um pólo industrial, por exemplo. Assim, nas atividades econômicas a escolha da localização ótima é algo fundamental e aborda questões sobre a proximidade das matérias-primas, redução dos custos de produção, custos com transportes, aumento dos lucros, entre outros fatores.

Nota-se que a preocupação com o crescimento desigual no espaço tem sido estudada por vários autores que objetivam analisar como se desenvolvem e crescem as regiões, muitos desses estudos têm influenciado a ciência regional, tornando-se um arcabouço teórico para a efetivação de políticas públicas. Nesse sentido, uma das teorias que possui uma grande importância na análise descrita é a TBE desenvolvida por Douglass North, que elucida o desenvolvimento econômico a partir de uma atividade exportadora, que fomentaria outras atividades que são voltadas ao mercado interno. Tal teoria será abordada na próxima seção, bem como seus principais fundamentos.

\section{A TEORIA DA BASE DE EXPORTAÇÃO}

A TBE, desenvolvida por Douglas North inicialmente em 1955, tinha por objetivo explicar o desenvolvimento da região ${ }^{6}$ como um processo que

6 Ao contrário de muitos autores, não se observa em North uma preocupação por conceituar região, a mesma é compreendida como área em que as atividades econômicas são desenvolvidas. 
tem sua origem ligada a um impulso externo, isto é, a demanda de seus produtos por outras regiões ou países, onde as exportações, através do efeito multiplicador, geram o desenvolvimento econômico da região.

Ao analisar a teoria da localização tradicional, North (1955) observa que o processo de desenvolvimento regional europeu é explicado a partir de certas fases pelas quais passaram algumas regiões do continente, tais como: um estágio de subsistência, rápido processo industrial, depois graças ao comércio inter-regional observa-se uma maior produção "forçando" a região se industrializar, e por fim uma região se especializada em produtos para exportação.

North (1977a p. 295), no entanto, ao estudar o desenvolvimento regional dos EUA verifica que o mesmo não passou necessariamente por estas fases e que as teorias de localização até então existentes, explicavam o desenvolvimento das regiões européias, mas não a americana. Dessa forma, utilizando-se de um dos pressupostos da Teoria da Base Econômica, a divisão das atividades econômicas em básica (aquelas que vendem seus produtos além das fronteiras da cidade) e não-básica (servem de apoio à atividade básica), assim como do pressuposto das chamadas regiões "jovens", ou seja, regiões com pouco processo de desenvolvimento ${ }^{7}$ (baixo nível de renda, uma pequena população), para explicar o desenvolvimento da região a partir das exportações.

A TBE utiliza do multiplicador keynesiano, seu conceito é similar ao da macroeconomia tradicional; há necessidade de definir as atividades exógenas situadas fora da economia regional ou que dependem de forças externas, como as exportações; determina-se o multiplicador observando o desenvolvimento histórico da base econômica, sendo este multiplicador aplicado para projeções da atividade total ou para medir impactos de variações na base exportadora sobre a economia regional, conforme equação abaixo;

$$
k=\frac{1}{1-b+m}
$$

Onde $b$ representa a propensão marginal a consumir e $m$ a propensão marginal a importar, recorrendo-se ao conceito keynesiano de injeção e

Não se tratando necessariamente de regiões subdesenvolvidas 
Teoria da base de exportação e sua relação com o desempenho econômico: o caso do estado de Santa Catarina

vazamento de renda. No caso de consumo interno, a renda é injetada nas despesas com produtos da região, e no caso das importações, a renda é vazada para consumir produtos derivados de importações.

Pode-se deduzir que as exportações apresentam um papel fundamental na determinação do nível de renda absoluta e per capita de uma região, ou seja, seriam, portanto, segundo North (1977a) o próprio motor que inicia o crescimento local e/ou regional, determinando seu alcance através do efeito multiplicador que as exportações produziriam sobre as outras atividades (Não-básicas).

No entanto, restaria uma pergunta: a existência de uma demanda externa de certo bem ou serviço seria o suficiente para explicar o desenvolvimento da região? Aparentemente não, isso então leva a uma segunda pergunta: o que mais seria necessário para que tal região se desenvolva?

North (1977a) justifica que as exportações são fatores necessários, mas não suficientes para explicar o desenvolvimento regional, sendo essencial analisar outras variáveis como a correlação entre as atividades básicas e não-básicas; custos de transferência e processamento etc. Segundo o autor, não há automatismo entre exportações e desenvolvimento regional, assim é primordial o atendimento de alguns requisitos para que uma região possam se desenvolver a partir das exportações.

Essa distinção aparece de forma esclarecedora no trabalho de Schwartzman (1973) ao distinguir entre condições necessárias e suficientes para o desenvolvimento da região. Como condições necessárias destacam:

- Distribuição dos recursos naturais pelas regiões;

- Custos de transferência (dependentes da localização da região)

- Custo de processamento (dependente da relação capital (K)/trabalho(L));

- Custo de processamento (fatores de produção);

- Algum nível de recurso ocioso para, no curto prazo, ser capaz de atender à demanda externa.

$\mathrm{O}$ autor infere que o processo inicia-se pelas vantagens locacionais especiais, que diminuem os custos de transferências e processamento dos bens 
ou serviços a serem exportados. Neste contexto, as indústrias subsidiárias (não-básicas), que servem à indústria de exportação (básica), assim como os bancos e outras atividades financeiras, também se concentram nesses centros e atuam para melhorar a posição do custo dos bens ou serviços a serem exportados.

Schwartzman (1973) afirma que as condições necessárias por si só não serão capazes de explicar o desenvolvimento da região a partir da demanda externa. Segundo ele, duas serão as condições suficientes para o desenvolvimento no longo prazo:

(i) Que haja um dinamismo do produto ser exportado para o resto da economia: é preciso que haja aumento da renda real, ou seja, que uma economia esteja crescendo para se falar em desenvolvimento econômico. Faz-se necessário que venda dos produtos de exportação esteja crescendo a uma taxa adequada, dentre outros fatores isso dependerá de dois fatores:

a) Elasticidade-renda da procura, que determina a possibilidade que tem a região de manter seu dinamismo através de um só produto de exportação; isto quer dizer que, se a elasticidade-renda for baixa, não haverá uma tendência secular para o aumento de suas vendas, à medida que as regiões compradoras se desenvolvam;

b) Custo do produto exportado, que estará associado diretamente aos custos de transporte e de produção, os quais dependerão também das variáveis de produção, tecnologia, disponibilidade de recursos, entre outros.

Uma segunda condição suficiente seria (ii) a difusão do dinamismo para outros setores da região. É preciso que outros setores da economia se desenvolvam paralelamente, ou seja,a distribuição de renda atinja o maior número de pessoas possível e que eventualmente apareçam outras bases de exportação. Schwartzman (1973) vai além, ao associar tal difusão às duas condições, são elas:

a) As características do produto de exportação, capazes de produzir encadeamentos importantes que podem ser para trás (insumos), para frente (criação de novas atividades produtivas) e de demanda final (investimentos na indústria local);

b) A diversidade dos recursos naturais da região, que se tornam importantes à medida que eles também poderão ser explorados conjuntamente com o aproveitamento da atividade-base. 
Teoria da base de exportação e sua relação com o desempenho econômico: o caso do estado de Santa Catarina

O que se infere do trabalho de Schwartzman (1973), é que ainda que aponte a importância das exportações no processo de desenvolvimento regional, não haveria por assim dizer um processo automático entre exportação e desenvolvimento regional. Seria preciso que a atividade básica provocasse efeitos sobre outros setores, ou seja, sobre as atividades não-básicas e que a renda se distribuísse razoavelmente entre a população, enfim as exportações, associadas às condições necessárias, seriam de suma importância, mas que sozinha não explicariam o desenvolvimento da região. Dessa forma, segundo o autor, para que uma região se desenvolva a partir das exportações faz-se preciso que tanto as condições necessárias quanto suficiente sejam preenchidas.

Ressalta-se que North afirma que a industrialização da região não precisa ser um pré-requisito fundamental para seu crescimento, já que nada impede que a população e a renda per capita cresçam em uma região cuja base de exportação seja agrícola (neste sentido a teoria da base demonstra ter viabilidade de aplicação na região selva central do Peru, por exemplo, cuja estrutura agregada depende diretamente do setor agrícola), e que não seria difícil desenvolver também a indústria secundária e terciária em tal região.

Neste ponto, North abre sua teoria principalmente para a aplicação em regiões subdesenvolvidas de caráter especificamente agrícola. Em seu artigo: “A Agricultura no Crescimento Econômico Regional", escrito em 1959, o autor tenta argumentar que uma produção bem sucedida de bens agrícolas (ou mesmo, de muitos produtos extrativos), destinados à venda fora da região, pode ser o principal fator de indução do crescimento econômico de uma região (NORTH, 1977b). Neste sentido, seriam também os produtos agrícolas capazes de fornecer à região o impulso inicial para a expansão geral, podendo mais tarde induzir à urbanização, ao aperfeiçoamento do mercado e a uma alocação mais eficiente dos recursos para o investimento.

Tiebout (1977) afirma que não existiria razão para supor que as exportações sejam a única ou mesmo a variável autônoma mais importante na determinação da renda regional. Outros itens como investimentos comerciais, despesas governamentais e volume de construções residenciais podem ser tão autônomos quanto as exportações, com respeito à renda regional. Ainda mais, quanto maior a região, menos importantes serão as exportações. Em resposta a esta crítica, North ponderou que as outras variáveis podem e geralmente são importantes numa análise de curto prazo, mas em longo prazo, quando 
não se pode supor a existência de recursos ociosos, a questão é diferente. Ele diz que é preciso conhecer a força iniciadora das mudanças e propulsora de outras atividades, que para ele continuam sendo as exportações.

Desta maneira, ainda com um arcabouço de restrições e críticas à TBE, deve-se deixar claro que esta não é uma teoria geral do desenvolvimento econômico regional. Como afirma North, ela só se aplica em regiões que tiveram o seu impulso de desenvolvimento originado no comércio exterior, dentro do contexto de instituições capitalistas. Além disso, a teoria foi desenvolvida para o contexto de economias "novas", sem pressão populacional e colonizada por pessoas de "espírito capitalista", que pretende nela se fixar.

Finalmente, a TBE procura explicar os fatores que determinam o desenvolvimento de regiões "novas" no longo prazo, tendo nas exportações a variável-chave, mas à medida que a região se desenvolve, ela amadurece e se torna mais complexa, implicando no surgimento de novos setores básicos e atividades internas que possam se auto-sustentar para a formação da maior parte de sua renda.

\section{METODOLOGIA}

Com vistas a analisar a dinâmica espacial e econômica de Santa Catarina, a partir da teoria da base exportadora, os procedimentos metodológicos utilizados foram as medidas de localização e especialização. De acordo com Haddad (1998), as medidas de localização são medidas de natureza setorial e se preocupam com a localização das atividades entre as regiões. O principal objetivo é identificar padrões de concentração ou dispersão espacial da variável-base, num dado período ou entre dois ou mais períodos.

As medidas de natureza regional se concentram na análise da estrutura produtiva de cada região, com o objetivo de investigar o grau de especialização das economias regionais num dado período, assim como o processo de diversificação observado entre dois ou mais períodos.

A variável base utilizada foi o emprego formal distribuído nos grandes setores do IBGE: Indústria, construção civil, comércio, serviços e agropecuária, nos anos de 1990, 2000 e 2010. Os dados foram obtidos na Relação Anual de Informações Sociais (RAIS) do Ministério do Trabalho e Emprego (MTE). As medidas empregadas foram: Quociente Locacional (QL) e o Coeficiente de reestruturação. 


\subsection{A matriz de informações}

As informações podem ser organizadas em uma matriz, na qual cada linha mostra a distribuição total do emprego de uma dada indústria, setor ou atividade entre as diferentes regiões de um país ou estado, e cada coluna mostra como o emprego total de uma dada região se distribui entre os seus diferentes setores industriais ou atividades.

Para a construção da matriz define-se:

$E_{i j}=$ emprego no setor $i$ da região $j$;

$E_{. j}=\sum_{i} E_{j}=$ emprego em todos os setores da região $j$;

$E_{i .}=\sum_{j} E_{j}=$ emprego no setor $i$ de todas as regiões;

$E .=\sum_{i} \sum_{j} E_{j}=$ emprego em todos os setores de todas as regiões.

Assim, pode-se apresentar a matriz de informação da seguinte forma:

Figura 1 - Matriz de Informação

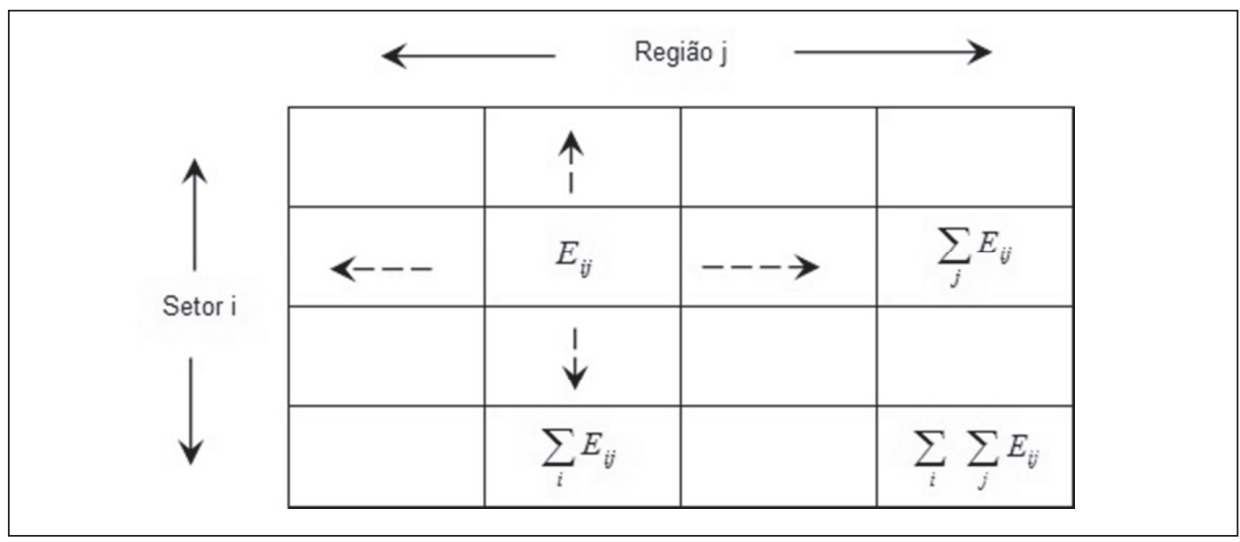

Fonte: Adaptado pelos autores com base em Haddad (1989).

A partir dessa matriz, são derivadas outras duas que mostram, em termos percentuais, a distribuição do emprego em cada região por setor produtivo, e a distribuição do emprego de cada setor produtivo entre as regiões: 


$$
\begin{gathered}
i^{e} j=\frac{E_{j}}{\sum_{i} E i j} \\
j^{e} i=\frac{E_{j}}{\sum_{j} E_{j}}
\end{gathered}
$$

sendo: $\sum_{i} i^{e} j=1,0 ; \sum_{j} j^{e} i=1,0 ; i^{e} .=\sum_{j} i^{e} j ;$ e $j^{e} .=\sum_{i} j^{e} i$

define-se, portanto, as duas equações abaixo:

$$
\begin{aligned}
& \mathrm{i}^{\mathrm{e}} \cdot=\sum_{\mathrm{j}} \mathrm{i}^{\mathrm{e}} \mathrm{j} \\
& \mathrm{j}^{\mathrm{e}} .=\sum \mathrm{j}^{\mathrm{e}} \mathrm{i}
\end{aligned}
$$

\subsection{Medidas de localização}

\subsubsection{Quociente locacional}

O quociente locacional do setor $i$ na região $j$ é definido como:

$$
Q L_{i j}=\frac{E_{j} / E_{i .}}{E_{. j} / E .}
$$

O quociente locacional (QL) compara a participação percentual de uma região, em um dos setores, com a participação percentual da mesma região, no total do emprego. Se o valor do quociente for maior do que 1, isto significa que a região é, relativamente, mais importante no contexto nacional, em termos do setor, do que em termos gerais de todos os setores.

Usualmente, com base nos Quocientes locacionais, considera-se como atividades básicas (de exportação) aquelas que apresentam um valor locacional superior a 1. Desta forma, esses setores constituem o motor do crescimento regional, visto que, ao exceder a demanda interna, tais setores seriam destinados à exportação. 
Teoria da base de exportação e sua relação com o desempenho econômico: o caso do estado de Santa Catarina

\subsubsection{Coeficiente de Reestruturação}

O coeficiente de reestruturação da região j é definido como:

$$
C R_{j}=\frac{\sum\left(\left|i^{e} j-i^{e} j\right|\right)}{2}
$$

sendo $\mathrm{i}^{\mathrm{e}} \mathrm{j}$ e $\mathrm{i}^{\mathrm{e}}$. definidas em (1) e (3), respectivamente.

O coeficiente de reestruturação objetiva analisar o grau de mudança estrutural da região, utilizando dois períodos. O Coeficiente varia de 0 a 1 , sendo que quando for próximo de 0 não terá acontecido mudanças na distribuição setorial da região e quando for igual a 1 terá ocorrido transformações no que concerne a especialização setorial da região.

\section{RESULTADOS E DISCUSSÕES}

\subsection{Formação histórica de Santa Catarina}

A ocupação em Santa Catarina pode ser justificada pela necessidade portuguesa de expandir sua influência para o Sul do Brasil, povoando e colonizando novos espaços geográficos. Remete-se ao século XVII a ocupação do estado, inicialmente nos povoados litorâneos: São Francisco (1645), Nossa Senhora do Desterro (1651), que hoje é Florianópolis, e Laguna (1676) (CÔRREA, 1999).

No período colonial, Santa Catarina exerceu o papel de intermediação geográfica entre a região de São Vicente e o Estuário da Prata, verificando-se posteriormente a ocupação de outras áreas. Côrrea $(1999$, p.27) afirma que o processo de tomada de terra em Santa Catarina ocorreu em consonância ao modelo adotado nacionalmente, “(...) através da concessão de sesmarias, que possuíam tamanhos variados, diferenciando-se também o critério de concessão."

A reduzida disponibilidade de recursos dos povoadores catarinenses influenciou para a impossibilidade da manutenção de latifúndios na região, visto que a população era predominantemente detentora de utensílios agrícolas e de mineração, gados e poucos escravos. A economia desenvolvida no litoral 
catarinense foi baseada na pequena propriedade familiar, devido a concessão de terra dada à população pela Coroa. Além de uma área de terra reduzida, as adversidades ambientais aumentaram as dificuldades de implantar as atividades produtivas na região. Devido a reduzida disponibilidade de instrumentos e recursos, as atividades agrícolas foram praticadas na região, com destaque para os produtos: mandioca, cana-de-açúcar, grãos e, em pequena escala, o trigo.

Tal movimento caracteriza o primeiro estágio de ocupação de Santa Catarina, baseado na reduzida capacidade financeira e por atividades de subsistência. Outro ponto central é que os incentivos iniciais para a colonização do estado se concentraram nos povoados litorâneos. Assim, o povoamento de Santa Catarina ficou restrito a essas áreas, criando uma segregação em relação às demais regiões. Na segunda metade do século XVIII surgiram as primeiras experiências com povoamento na região serrana, em especial na região de Lages.

As primeiras atividades artesanais contribuíram para o crescimento posterior de indústrias no estado. Ademais, a estrutura geográfica e econômica foi resultante do povoamento heterogêneo e de uma especialização regional diferenciada em cada atividade produtiva. Desta forma, Santa Catarina apresenta seis pólos relevantes, sendo cinco predominantemente industriais e um, Florianópolis, eixo mais administrativo.

Figura 1: Mapeamento da divisão de Santa Catarina

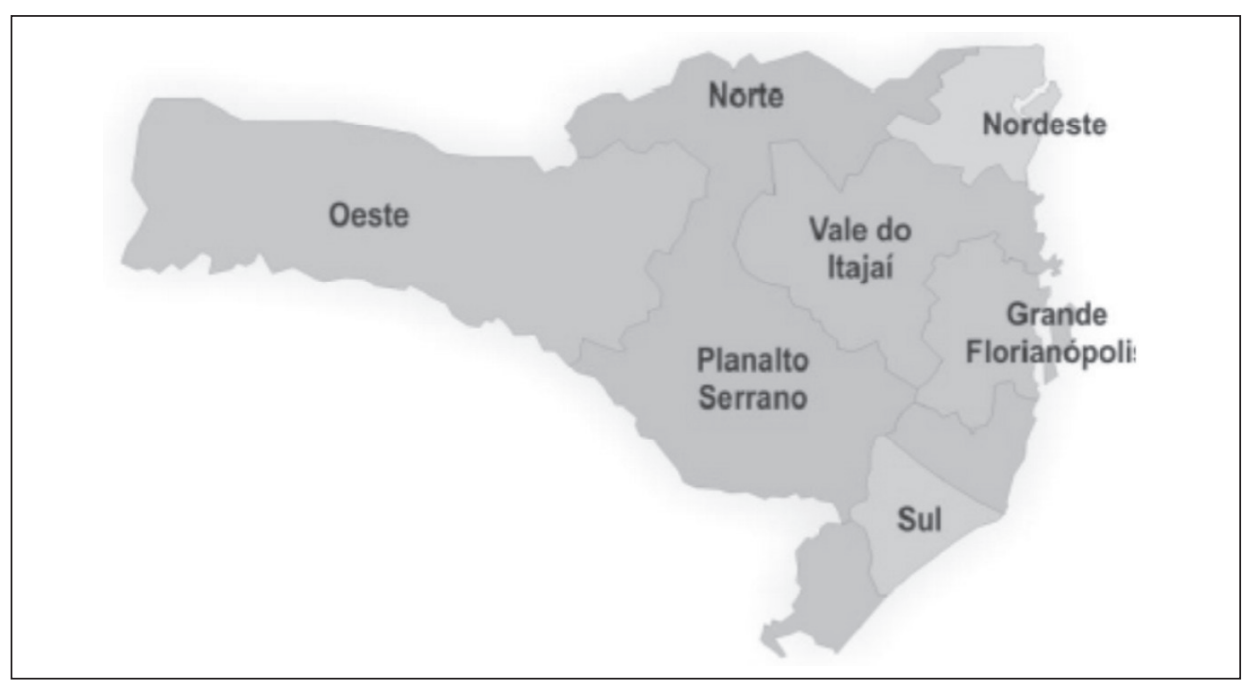

Fonte: Secretaria do Estado de Desenvolvimento Econômico Sustentável (2009) 
A região de Florianópolis é caracterizada pela concentração de atividades público-administrativas, pelo complexo pesqueiro, indústria náutica, setor de turismo e importante pólo tecnológico e setor terciário. A região Norte e Nordeste de Santa Catarina é fortemente especializada no setor metal-mecânico, atividades têxteis e alimentícias, atividades atacadistas, turismo e fruticultura.

O Vale do Itajaí é intensamente especializado no setor secundário e apresenta relevância em tais atividades: atividades têxteis, alimentícias, bebidas, calçadista, tecnológico, cerâmica, turismo e comércio varejista. O Sul catarinense ganha destaque pelas atividades de cerâmica, plástico, têxtil, alimentícia e comércio varejista (Souza e Barros, 2011).

A economia do Planalto Catarinense é predominantemente caracterizada pela atividade pastoril, herdada do processo de formação da região. Verifica-se a existência também de atividades industriais de papel e celulose, mecânica, de alimentos, bebidas e madeireira. Por último, o Oeste catarinense é uma região de destaque econômico no contexto nacional, especialmente pela agroindústria. A região também apresenta uma estrutura setorial diversificada, evidenciada a presença do setor de serviços, comércio e transportes.

\subsection{Análise dos dados}

De acordo com os dados do IBGE, em 2010, Santa Catarina apresentou uma população estimada em 6.248.436 habitantes, representando 3,3\% da população brasileira e uma densidade demográfica de 65,29 (hab/ $\left./ \mathrm{km}^{2}\right)$. O gráfico 1 mostra a divisão população de acordo com o critério dos residentes na área urbana ou rural de Santa Catarina.

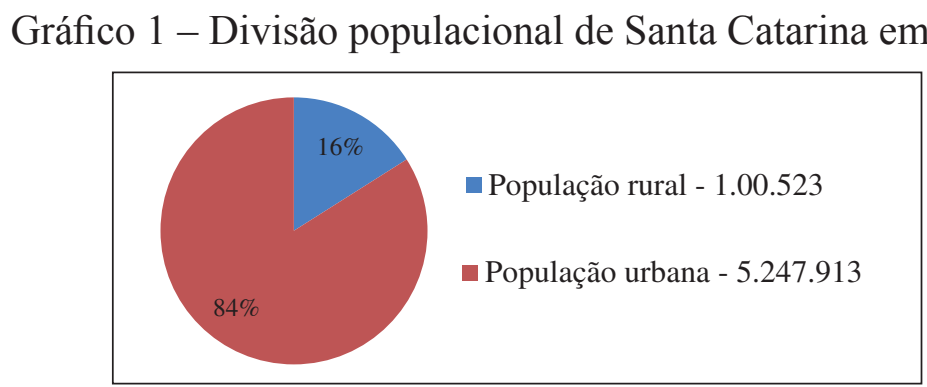

Fonte: IBGE, Censo Demográfico (2010). 
A análise da estrutura produtiva de Santa Catarina mostra que o setor terciário e a indústria são os mais representativos para a economia estadual. De acordo com os dados dos empregos formais (tabela 1), verifica-se a evolução da variável em todos os setores econômicos no estado. O setor de serviços, tal como ocorre no cenário nacional, é o que apresenta o maior número de empregos, afirmando o processo de terceirização em Santa Catarina. Quando se analisa a participação do emprego em relação ao Brasil, a indústria é o setor mais representativo, corroborando para a potencialidade industrial do estado.

Tabela 1 - Distribuição setorial do emprego formal em SC: 1990, 2000 e 2010

\begin{tabular}{l|c|c|c|c|c|c}
\hline & \multicolumn{2}{|c|}{1990} & \multicolumn{2}{c|}{2000} & \multicolumn{2}{c}{2010} \\
\hline & Total & $\begin{array}{c}\text { \% } \\
\text { (Brasil) }\end{array}$ & Total & $\begin{array}{c}\text { \% } \\
\text { (Brasil) }\end{array}$ & Total & $\begin{array}{c}\% \\
\text { (Brasil) }\end{array}$ \\
\hline Indústria & 337.605 & 5,70 & 388.120 & 7,34 & 655.295 & 7,71 \\
\hline Construção civil & 18.882 & 1,97 & 37.519 & 3,43 & 89.045 & 3,55 \\
\hline Comércio & 108.612 & 3,65 & 181.722 & 4,27 & 395.888 & 4,72 \\
\hline Serviços & 344.956 & 3,07 & 440.703 & 3,03 & 786.321 & 3,38 \\
\hline Agropecuária & 14.790 & 3,97 & 29.813 & 2,78 & 43.105 & 3,06 \\
\hline
\end{tabular}

Fonte: Elaboração própria dos autores a partir dos dados da RAIS (2012)

A partir da década de 1990 é possível verificar que Santa Catarina passou por modificações no que concerne sua estrutura produtiva (Gráfico 2). De acordo com os resultados do QLs, o setor industrial apresenta grande potencialidade no estado, visto que o QL $>1$ em todos os anos de análise indica que há um padrão de concentração industrial no estado. Em contrapartida, a agropecuária vem sofrendo um processo de redução da sua representatividade, com pequena elevação no período de 2000 a 2010.

Outro ponto de destaque é a crescente participação do setor de construção civil, corroborado pela elevação do QL setorial. Entretanto tal aumento não significou a especialização do estado no setor, tendo em vista que em nenhum ano o QL foi maior que 1. A agropecuária apresentou uma elevação em 2010, entretanto tal aumento não atingiu o QL que o setor apresentou em 1990 . 
Teoria da base de exportação e sua relação com o desempenho econômico: o caso do estado de Santa Catarina

Gráfico 2 - Quociente locacional em Santa Catarina: 1990, 2000 e 2010

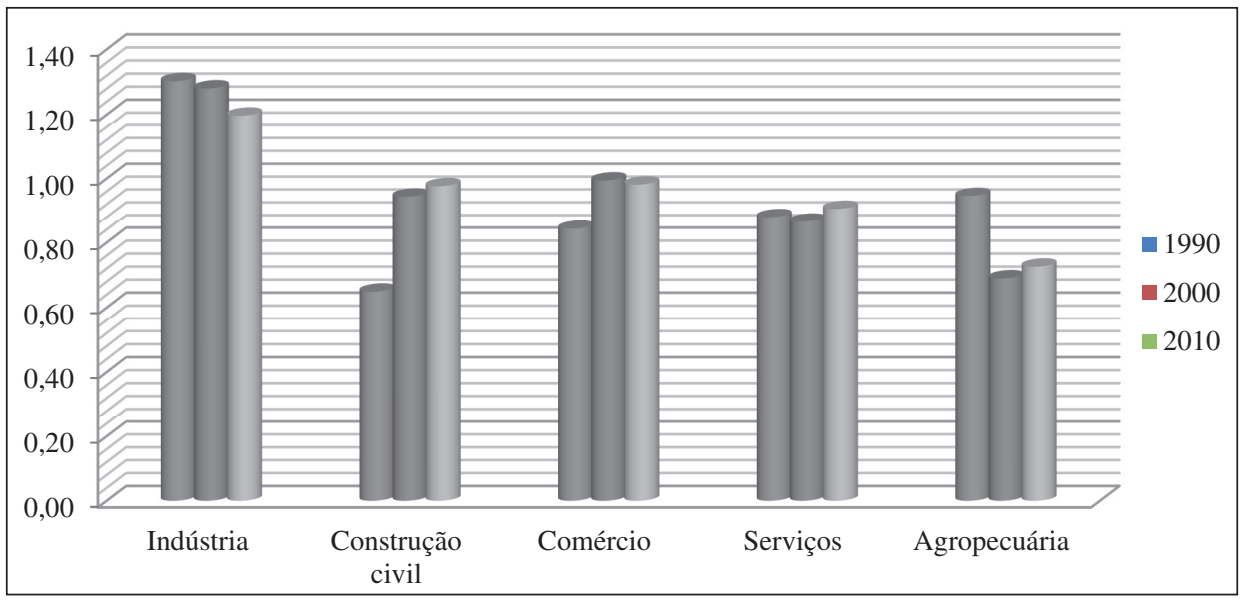

Fonte: Resultado da Pesquisa.

Dessa forma, os resultados do QL indicam que o estado de Santa Catarina apresenta forte concentração no setor industrial, reafirmando para esse setor o papel central para o dinamismo regional. A indústria santa catarinense constitui o motor do crescimento regional, visto que o QL>1 sugere que o setor excede a demanda do mercado interno e é destinado a exportação, caracterizando como a atividade básica (exportação) do estado. Ademais, segundo a TBE, tal setor é o responsável pelo desempenho interno e para propagar este dinamismo para os demais setores: as atividades não básicas.

Outro resultado obtido foi que o estado apresentou um coeficiente de reestruturação de 0,096 no período de 2000 e 2010. Esse resultado indica que não ocorreram mudanças significativas na estrutura econômica de Santa Catarina, confirmando o padrão de especialização industrial vivenciado no estado.

O gráfico 3 mostra o valor adicionado de cada setor ao PIB de Santa Catarina. Verifica-se que o setor de serviços é o mais representativo, posição essa alcançada a partir de 2002 quando o setor elevou sua participação em detrimento da perda da indústria. A indústria é caracterizada por uma forte oscilação ao longo do período, indicando uma forte perda de participação de 2001 para 2002. 
Gráfico 3 - Valor adicionado da indústria, Serviços e Agropecuária em SC (preços básicos - 2000)

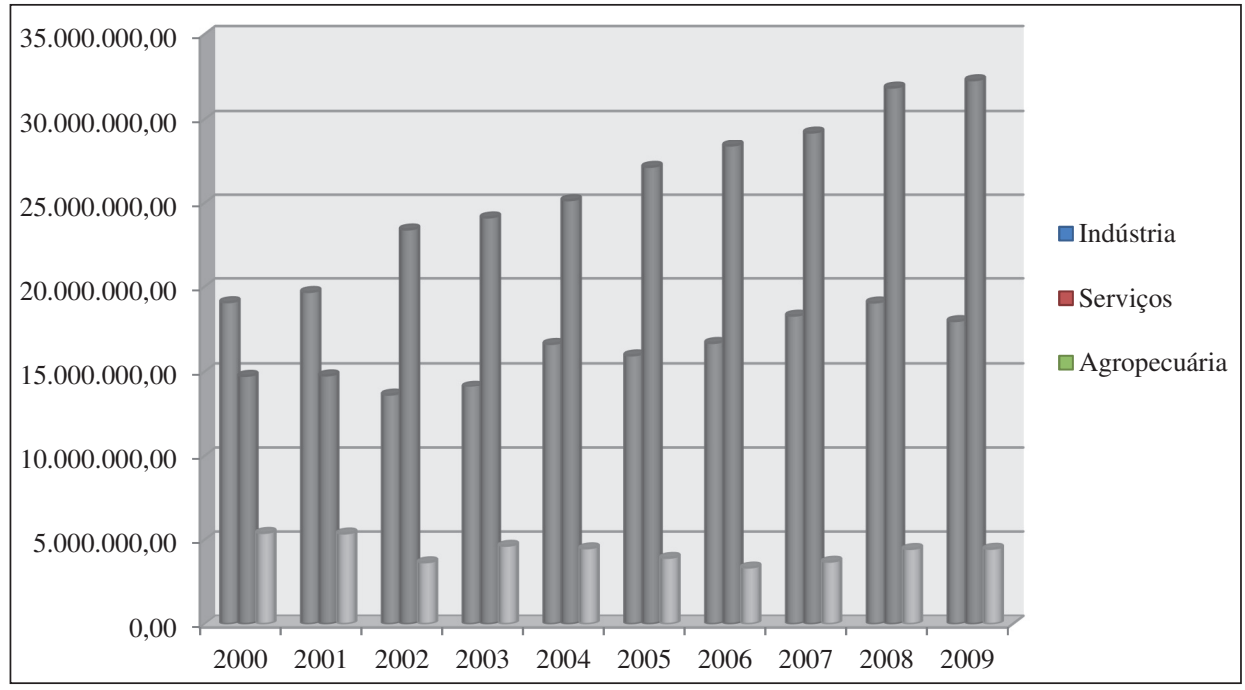

Fonte: Elaboração própria dos autores com base nos dados do IPEADATA

A partir dos dados do QL e do valor adicionado do setor industrial pode-se inferir que o estado apresenta uma forte concentração setorial, mas que ao longo do período vem perdendo sua representatividade. Segundo Oreiro e Feijó (2010) mudanças como essa são preocupantes, pois a indústria possui características especificas que a distingue dos demais setores, tais como: efeitos multiplicadores dinâmicos para o conjunto da estrutura produtiva; pela presença de economias de escala (estáticas e dinâmicas), o que significa que sua produtividade cresce com o aumento da produção; uma maior capacidade de geração e difusão do progresso técnico; a elasticidade renda das importações de produtos industriais é maior do que a dos produtos primários.

O gráfico 4 mostra a evolução do saldo comercial em Santa Catarina no período pós 2000. É possível notar a elevada deterioração do saldo, principalmente a partir de 2008. Deduz que a redução do setor industrial no estado pode condicionar o desempenho do saldo comercial, visto que a indústria, ao ser o setor chave da economia, não serviu como elemento de formação do efeito multiplicador sobre as demais atividades não-básicas. 
Teoria da base de exportação e sua relação com o desempenho econômico: o caso do estado de Santa Catarina

Gráfico 4 - Evolução do Saldo Comercial em Santa Catarina: 2000 a 2010 (Em Mil US\$)

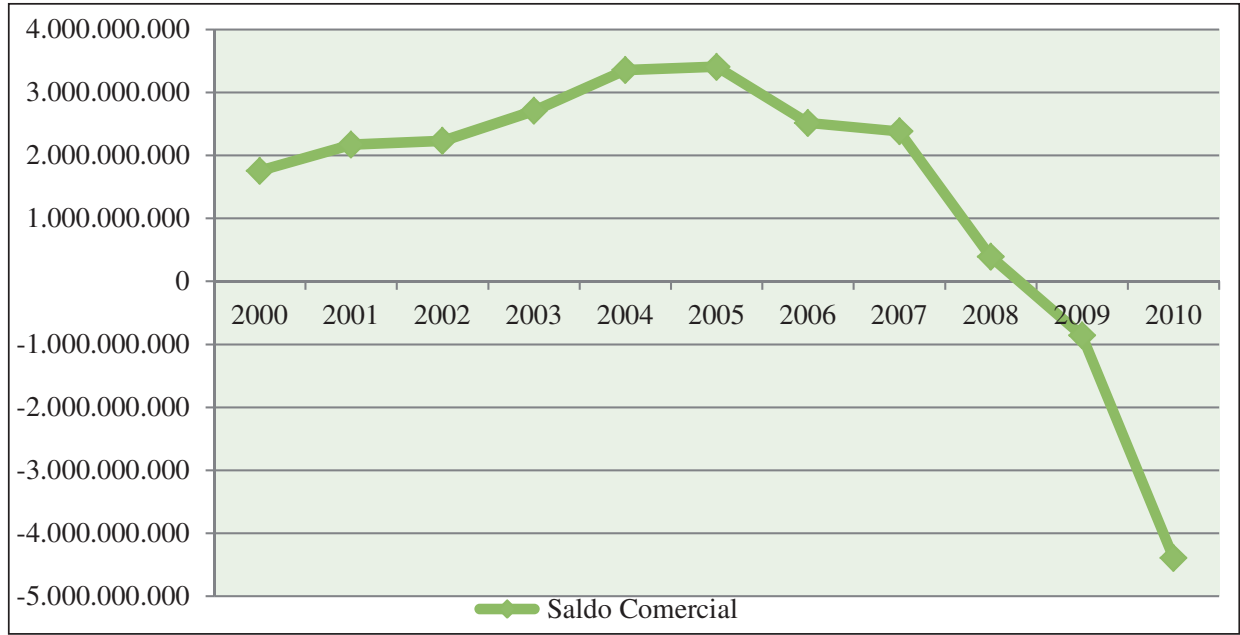

Fonte: Elaboração própria dos autores a partir dos dados do MDIC

Em suma, a base de exportação do estado não propiciou a diversificação setorial para outras atividades, resultando em poucas mudanças estruturais significativas e a forte dependência do desempenho do setor industrial para a dinâmica de Santa Catarina, expondo certa vulnerabilidade ao processo de desindustrialização pela qual vem passando o país. Desta forma, ressaltase a relevância de pensar em setores estratégicos e políticas públicas que possibilitem uma menor concentração produtiva.

\section{CONSIDERAÇÕES FINAIS}

O presente artigo teve por objetivo analisar a dinâmica recente da economia catarinense, a partir da teoria da base exportadora. Realizou-se um levantamento das concepções teóricas acerca da temática espacial e regional, bem como sobre a TBE. Constatou-se que a indústria representa o setor básico da economia de Santa Catarina, compondo assim o segmento primordial para o crescimento regional. O QL maior que 1 em todos os anos de análise reafirmou a potencialidade industrial do estado, bem como sua importância para o desempenho da economia catarinense. 
Os principais resultados indicaram que o estado não passou por uma mudança significativa na sua estrutura produtiva, já que sua especialização está voltada ao setor industrial. Entretanto, verificou-se a tendência de redução do QL da indústria e, em contrapartida, a elevação do QL da construção civil e comércio. $\mathrm{O}$ valor adicionado setorial reafirmou a perda do peso da indústria em detrimento da crescente participação do setor terciário no PIB do estado.

Dessa forma, é plenamente coerente com a TBE esse descolamento entre o crescimento industrial e o serviço, pois à medida que ocorre $\mathrm{o}$ desenvolvimento da atividade básica isso provoca um efeito sobre outros setores (não-básicos), desenvolvendo-os também. Para que uma região se desenvolva a partir das exportações faz-se preciso que tanto as condições necessárias (distribuição de recursos naturais; presença de recursos ociosos; custos- processamento e transporte) como suficientes (dinamismo do setor básico e uma interdependência com os demais setores) sejam preenchidas causando uma maior dinâmica regional. No entanto, no estado de Santa Catarina no período em análise, não se observou uma completa realização das condições suficientes. A redução do peso da indústria e o maior dinamismo das demais atividades não fizeram surgir novos setores básicos, fato este comprovado através da elevada deterioração do saldo da balança comercial apresentada no período.

Em suma, as constatações do trabalho sugerem a importância de políticas públicas que priorizem o crescimento de outros setores estratégicos e possibilitem uma menor concentração setorial, visto que a economia catarinense tem seu desempenho atrelado à dinâmica industrial.

\section{THEORY OF THE BASIS OF EXPORT AND THE RELATION TO ECONOMIC PERFORMANCE: THE CASE OF THE STATE OF SANTA CATARINA}

\section{Abstract}

This paper aims to examine the economic performance of the state of Santa Catarina from the theoretical framework of the Export Base Theory. Analyzes the sectoral distribution of activities in the state to identify what are the key sectors for their performance in the period post 1990. In order 
to meet this goal, we carried out a theoretical construct on the theme and used the methods of regional analysis and specialization, specifically Locational Quotient (LQ) and the coefficient of Restructuring. Results indicated that the industry is the basic (export) the states economy, reaffirming its pattern of specialization in the sector. Moreover, the export base of the state did not provide the growth of other export activities, although it has seen the loss of value added of industry at the expense of the increase of the service sector in the last decade. Thus, it emphasizes the importance of thinking in strategic sectors and policies that enable a lower concentration of production and greater sector diversification.

Keywords: Base export, economic, Santa Catarina.

\section{JEL Classification: R10}

\section{REFERÊNCIAS}

AREND, Sílvio Cezar; ORLOWSKI, Rosemari Fátima. O desenvolvimento regional da AMOSC a partir das teorias da base exportadora e dos pólos de crescimento. REDES, Santa Cruz do Sul, v. 17, n. 1, p. $141-163$, jan/abr 2012

BENKO, G. A Ciência Regional. Oeiras (PO)1999.

CLEMENTE, A. Economia regional e urbana. São Paulo. Atlas, 1994.

CÔRREA, Walquíria Kruger. Considerações sobre a formação territorial e econômica de Santa Catarina. Revista Geosul, Florianopolis, v. 14, n. 27, 1999.

IBGE. Instituto Brasileiro de Geografia e Estatística. Disponível em: http://www.ibge.gov.br. Acesso em fevereiro de 2013.

IPEADATA. Banco de Dados do Instituto de Pesquisa em Economia Aplicada (IPEA). Disponível em: http://www.ipeadata.gov.br/ipeaweb.dll/ ipeadata?192810671. Acesso em fevereiro de 2013. 
LIMA, Ana Carolina da Cruz; SIMÕES, Rodrigo Ferreira. Teorias do desenvolvimento regional e suas implicações de política econômica no pós-guerra: o caso do Brasil. Belo Horizonte: UFMG/Cedeplar, 2009.

MDIC. Ministério do Desenvolvimento, Indústria e Comércio Exterior. Estatísticas de Comércio Exterior (DEPLA). Disponível em: http://www. desenvolvimento.gov.br/sitio/interna/interna.php?area $=5 \&$ menu $=1161$. Acesso em fevereiro de 2013.

PERROUX, F. A economia do século XX. Trad. José Lebre de Freitas. Lisboa: Herder, 1967.

SCHARTZMAN, Jacques. O desenvolvimento da teoria da base de exportação como uma teoria do crescimento. Belo Horizonte: CEDEPLAR - UFMG, 1973 (Tese mestrado)

NORTH, Douglass C. Teoria da localização e crescimento econômico regional. In: Schwartzman, J. Economia regional: textos escolhidos. Cedeplar, Belo Horizonte, 1977a

NORTH, Douglass. A agricultura do crescimento econômico regional. In: SCHWARTZMAN,J.(Org.).economia regional: textos selecionados. Belo Horizonte:CEDEPLAR,1977b

TIEBOUT, Charles M. As exportações e o crescimento econômico regional. In: Schwartzman, J. Economia regional: textos escolhidos. Cedeplar, Belo Horizonte, 1977.

SOUZA, Joel José; BASTOS, Maycon Neykiel. A formação socioespacial do estado de Santa Catarina, Brasil. Revista Geográfica de América Central, Número Especial EGAL, 2011. 